\title{
Overexpression of Long Non-Coding RNA ZXF2 Promotes Lung Adenocarcinoma Progression Through c-Myc Pathway
}

\author{
Ze-Tian Yang ${ }^{a}$ Zhihong Lib Xian-Guo Wang ${ }^{a}$ Tao Tan ${ }^{c}$ Frank Yic Hua Zhu ${ }^{c}$ \\ Jin-Ping Zhao ${ }^{a}$ Xue-Feng Zhou ${ }^{a}$
}

\begin{abstract}
aDepartment of Thoracic and Cardiovascular Surgery, Zhongnan Hospital of Wuhan University, Wuhan, P.R.China; 'bivision of General Surgery, Chenzhou First People's Hospital, Chenzhou, China; 'Department of Surgery, Davis Heart and Lung Research Institute, the Ohio State University Wexner Medical Center, Columbus, OH, USA
\end{abstract}

\section{Key Words}

LncRNA ZXF2 • Lung adenocarcinoma • Cell proliferation • Migration and invasion • c-Myc

\begin{abstract}
Objective: To investigate the expression of long non-coding RNA ZXF2 in lung adenocarcinoma tissues and its effect on cell proliferation, migration and invasion. Methods: Forty pairs of cancerous and adjacent non-cancerous lung adenocarcinoma specimens were collected for the studies. Quantitative real-time PCR was used to analyze the expression of ZXF2 in tumor tissues and adjacent normal tissues. The expression of ZXF2 was correlated with patients' clinico-pathological data. Molecular pathway controlled by ZXF2 was explored by using small interfering RNA (siRNA) technology. CCK-8 cell proliferation assay, flow cytometry analysis and transwell assays were used to evaluate cell proliferation, migration and invasion. Results: The expression of ZXF2 was 2 fold or higher in 27 out of 40 (67.5\%) cases of lung adenocarcinoma specimens than that in non-cancerous tissues $(P<0.05)$. The relative expression level of ZXF2 was positively correlated with tumor lymph node metastasis $\left(\chi^{2}=8.485, P<0.05\right)$ and poor prognosis of the patients $(p=0.0217)$. In order to explore the molecular mechanisms of ZXF2 mediated tumor progression, ZXF2 expression was inhibited by siRNA in A549 cells, a highly aggressive and metastatic lung adenocarcinoma cell line. We found that siRNA-ZXF2 treatment inhibited cell proliferation $(P<0.01)$ leading to cell cycle arrest $(P<0.01)$. The cell migration and invasion were suppressed by siRNA-ZXF2 treatment $(P<0.01)$. Further biochemical studies revealed that the knockdown of ZXF2 led to down regulation of c-Myc signaling. Conclusion: ZXF2 was overexpressed in lung adenocarcinoma tissues and the high expression of ZXF was closely related to tumor progression through c-Myc related pathway. Given the fact that both ZXF2 and c-Myc are located in the same chromosome 8q24.2 loci, the potential interaction between ZXF2 and c-Myc might be a novel target for treatment of lung adenocarcinoma.
\end{abstract}

Copyright (C) 2015 S. Karger AG, Basel

Jin-Ping Zhao, MD, Ph.D.

and Xue-Feng Zhou, MD, Ph.D.
Department of Thoracic and Cardiovascular Surgery,Zhongnan Hospital of Wuhan

University, 169 Donghu Road,Wuchang, Wuhan, Hubei, 430071 (P.R.China)

E-Mail Jasonmylive@gmail.com, E-Mail jasonmyth@hotmail.com 


\section{Cellular Physiology Cell Physiol Biochem 2015;35:2360-2370 \begin{tabular}{l|l} 
and Biochemistry Published online: April 15, 2015 & $\begin{array}{l}\text { C 2015 S. Karger AG, Basel } \\
\text { www.karger.com/cpb }\end{array}$ \\
\hline
\end{tabular} \\ Yang et al.: Oncological Roles of LncRNA ZXF2 in Lung Cancers}

\section{Introduction}

Long chain of non-coding RNAs (LncRNAs), a class of non-coding transcripts longer than 200 bps, are involved in regulating gene expression on a variety of levels including epigenetic, transcriptional and post-transcriptional regulations [1-3]. Recently, lncRNAs have attracted a broad attention for their function in X-chromosome silence, genomic imprinting and chromatin modification, transcription activation, transcription interference and nuclear transport, among others. Previous studies suggested an important role of lncRNAs in tumor progression [4]. For example, high expression of lncRNAs, such as BANCR, LSINCT5, HULC are closely related to the high incidence of melanoma, breast cancer and liver cancer [5-7]. However, the role of lncRNAs in lung adenocarcinoma remains largely unknown.

In our previous study, we screened human lung adenocarcinoma and non-cancerous tissues by Arraystar IncRNA gene chip and found that a group of lncRNAs are differently expressed in cancer and adjacent normal tissues [8]. In the present study, we verified our findings by comparing the expression of IncRNAs in cancer tissues and adjacent normal tissues derived from 40 patients with lung adenocarcinoma. We found a lncRNA, named ZXF2 (SEQ_ID: AA311918, located on chromosome 8, loci 8q24.2) had an average of 8.879 fold higher expression in lung adenocarcinoma tissues than that in non-cancerous tissues. Further analysis revealed that overexpression of ZXF2 was correlated with high lymph node metastasis and poor prognosis. Further study on the molecular mechanisms underlying ZXF2 meditated tumor progression, we found that siRNA mediated suppression of ZXF2 led to cell cycle arrest and inhibition of cell proliferation, migration and invasion through regulating c-Myc, a strong proto-oncogene which is located adjacent to ZXF2 in chromosome loci 8q24.2, a common location for multiple tumors.

\section{Materials and Methods}

\section{Patients and specimens}

Forty pairs of samples were obtained from patients with lung adenocarcinoma, who were treated in the Department of Cardiothoracic Surgery, Zhongnan Hospital, Wuhan University. Average length of tumor tissue was $2.4 \mathrm{~cm}$, average age of patients was 62 years old. All of the non-cancerous tissues were more than $5 \mathrm{~cm}$ away from tumor tissues. These patients underwent surgical resection of tumors and were pathologically diagnosed with lung adenocarcinoma (stage I, II and III) between June 2010 and June 2012. The clinicopathological parameters of the patients were summarized in Table 1 . None of the patients received chemotherapy and radiotherapy before surgery. The study was approved by The Human Research Ethics Committee of Wuhan University.

\section{Real-time RT-PCR}

Quantitative Real-time RT-PCR (qRT-PCR) was performed using FastStart Universal SYBR Green Master (Rox) kit on an ABI 7300 real time PCR System. ACTIN was used as internal control. The relative expression levels of ZXF2 were determined by normalizing expression of ZXF2 to that of ACTIN. ZXF2 primer sequence, sense: 5'-CAC CCA GGT CAG AGA AAG CA-3'; antisense: 5'-TGG AAG GGA CAC TAG AAG AAG AAT-3'. ACTIN primer sequence, sense: 5'-CAC CCA GCA CAA TGA AGA TCA AGA T-3'; antisense: 5'-CCA GTT TTT AAA TCC TGA GTC AAG C-3'. We defined positive expression of ZXF2 as a greater than 2 fold increase in carcinoma tissues than that in non-cancerous tissues.

\section{ZXF2 siRNA transfection}

Three siRNA sequences specifically against ZXF2 and control scramble siRNA (siRNA-NC, as a negative control) were synthesized from Gene-pharma (shanghai, China). SiRNA against ZXF2 and scramble siRNA were then transfected by lipofectamine 2000 reagent (Invitrogen, Carlsbad, CA, USA). The efficiency of siRNAs was determined by comparing expression of ZXF2 in siRNA treated cells to that in siRNA-NC treated cells. 


\section{Cellular Physiology Cell Physiol Biochem 2015;35:2360-2370

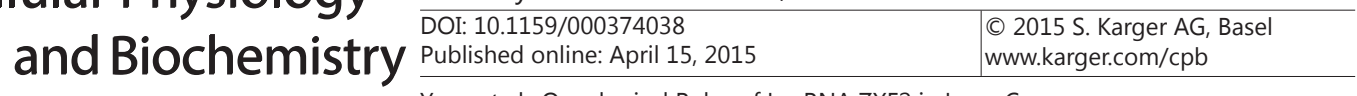 \\ Yang et al.: Oncological Roles of LncRNA ZXF2 in Lung Cancers}

Cell proliferation assay by CCK-8

To determine the effect of ZXF2 on cell proliferation, A549 cells transfected with siRNAZXF2 were seeded into 96well plates at a density of $3 \times 10^{3}$ cells/well and incubated for $24 \mathrm{~h}, 48 \mathrm{~h}$, $72 \mathrm{~h}$, and $96 \mathrm{~h}$, respectively. SiRNA-NC treatment was used as a negative control. The effect of ZXF2 on cell proliferation was determined by using cell count kit-8 (CCK-8) (Boster,China) as described previously [9]. Briefly, at the end of incubation, $10 \mu \mathrm{l}$ of CCK-8 solution was added to each well. Four hours later, the number of viable cells was determined by the absorbance of water-soluble formazan at 460 nm using a FlexStation 3 plate reader (Molecular Devices, CA).

\section{In vitro migration and invasion assays}

The procedure was described previously [10]. In brief, in vitro cell migration was examined in Boyden chamber system. A549 cells $\left(1 \times 10^{5}\right)$ treated with either siRNA against ZXF2 or siRNA-NC suspended in serum-free medium were added to the upper chamber $(6.5-\mathrm{mm}$ diameter, $8-\mu \mathrm{m}$ pore size, Corning), and the chamber was placed in 24-well dishes. Migration was permitted for $24 \mathrm{~h}$, and cells were then fixed with $4 \%$ formaldehyde.

In vitro cell invasion assays were conducted using a Boyden chamber $\left(2 \times 10^{5}\right.$ cells per well $)$ with Matrigel-coated invasion inserts (BD Biosciences, $8 \mu \mathrm{m}$ pore membranes) placed according to the manufacturer's instructions.

Twenty-four hours after incubation, trans-

Table 1. Relative ZXF2 level in tumor tissues of the patients with lung cancers

\begin{tabular}{|c|c|c|c|}
\hline Patient No. & Relative ZXF2 levels & Patient & No.Relative ZXF2 levels \\
\hline 1 & 3.530 & 21 & 1.880 \\
\hline 2 & 8.950 & 22 & 6.330 \\
\hline 3 & 9.730 & 23 & 19.150 \\
\hline 4 & 0.140 & 24 & 0.800 \\
\hline 5 & 15.700 & 25 & 2.840 \\
\hline 6 & 20.130 & 26 & 20.030 \\
\hline 7 & 0.560 & 27 & 17.050 \\
\hline 8 & 10.110 & 28 & 0.880 \\
\hline 9 & 0.350 & 29 & 1.560 \\
\hline 10 & 5.600 & 30 & 2.050 \\
\hline 11 & 0.840 & 31 & 18.340 \\
\hline 12 & 11.810 & 32 & 20.330 \\
\hline 13 & 4.600 & 33 & 0.050 \\
\hline 14 & 14.770 & 34 & 5.700 \\
\hline 15 & 1.200 & 35 & 12.990 \\
\hline 16 & 1.826 & 36 & 10.700 \\
\hline 17 & 4.130 & 37 & 6.800 \\
\hline 18 & 7.810 & 38 & 0.770 \\
\hline 19 & 9.560 & 39 & 7.540 \\
\hline 20 & 0.030 & 40 & 2.160 \\
\hline
\end{tabular}

migrating cells on the underside of the inserts were fixed with $4 \%$ formaldehyde and stained with 4 ',6-diamidino-2-phenylindole (DAPI). Fluorescent images of five random fields were acquired, the average number of cells per field was calculated and presented.

\section{Western blot}

Protein was extracted from cells by RIPA buffer. The protein lysate was separated by $12.5 \%$ SDS-PAGE, and electrophoretically transferred to a PVDF (polivinylidene difluoride) membrane (Roche). Then, the membrane was probed with antibodies against c-myc (Proteintech), e-cadherin (Proteintech) and GAPDH (as an internal control) (Proteintech); and horseradish peroxidase-conjugated secondary antibodies (Pierce Biotechnology, Rockford, IL). The chemiluminescence of proteins on PVDF membranes was detected with ECL Plus kit (Pierce).

\section{Cell cycle and apoptosis assay}

The cells were harvested after transfection with siRNA against ZXF2 and siRNA-NC for 48 hours. Then the cells were subjected to either cell cycle detection kit (Beyotime, China) or cell apoptosis detection kit (Sungene, China) by using a FACS Calibur instrument (Becton Dickinson, CA, USA).

\section{Statistical analysis}

Statistical analyses were conducted using SPSS17.0 software. Student's T test was used for paired data. Composition ratio was used to describe counting data. Chi-square test was used for clinical data analysis. Survival curves were plotted by Kaplan-Meier method and log-rank method. P values of $<0.05$ were considered statistically significant. 


\begin{tabular}{|c|c|c|}
\hline Cellular Physiology & Cell Physiol Biochem 2015;35:2360-2370 & \\
\hline and Biochemistry & $\begin{array}{l}\text { DoI: 10.1159/000374038 } \\
\text { Published online: April 15, } 2015\end{array}$ & $\begin{array}{l}\text { O } 2015 \text { S. Karger AG, Basel } \\
\text { www.karger.com/cpb }\end{array}$ \\
\hline
\end{tabular}

\section{Results}

ZXF2 overexpresses in lung adenocarcinoma and the expression is negatively correlated with patients' prognosis

Wecollectedcancerandadjacentnormaltissuesfrom 40 patientswithlungadenocarcinoma and analyzed the expression of ZXF2 in these samples by qRT-PCR. As shown in Fig. 1A and Table 1, the expression of ZXF2 in tumor tissue is significantly higher than that in adjacent normal tissues (with a mean increase of 7.23 fold, and a median increase of 5.56 fold). In addition, 27 out of 40 cancer tissues (67.5\%) had a 2 fold or higher expression of ZXF2 than that in adjacent non-cancerous tissues $(\mathrm{p}<0.05)$. This result confirm our previous observation[8].

Fig. 1. Expression of LncRNA ZXF2 in lung cancer tissues and its correlation with patients' postoperative survival. (A) LncRNA ZXF2 is overexpressed in tumor tissues as compared to adjacent normal tissue. 40 pairs of specimens were detected by qRT-PCR. 27 out of 40 cancer tissues had 2 fold or more lncRNA-ZXF2 than adjacent non-cancerous tissues $(\mathrm{P}<0.01)$. (B) The post-operative survival time was determined by Kaplan-Meier survival analysis. Compared with those in low ZXF2 group, the patients in high ZXF2 group had significant shorter survival time $(\mathrm{P}=0.0217)$.

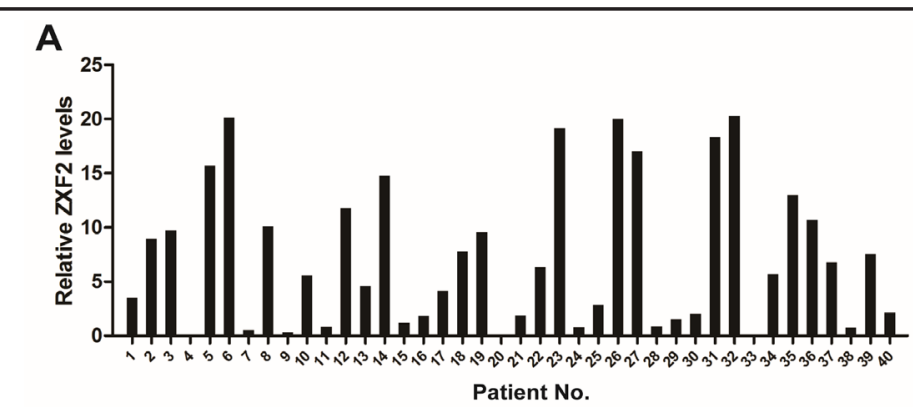

B

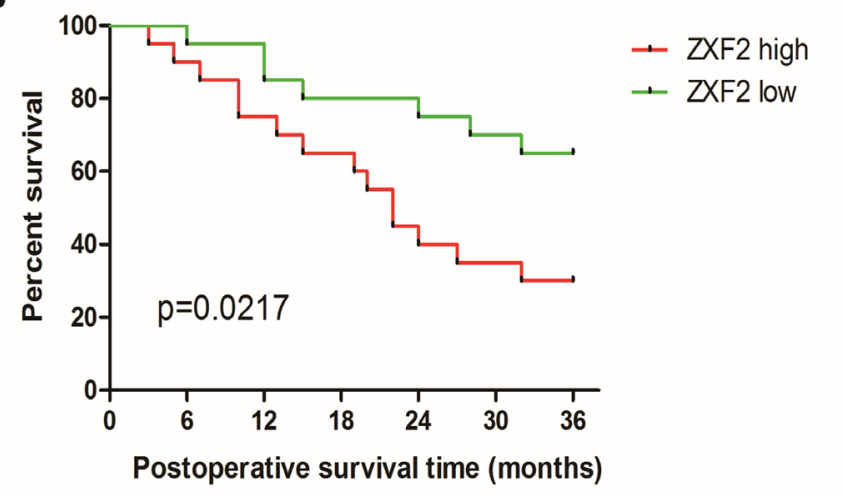

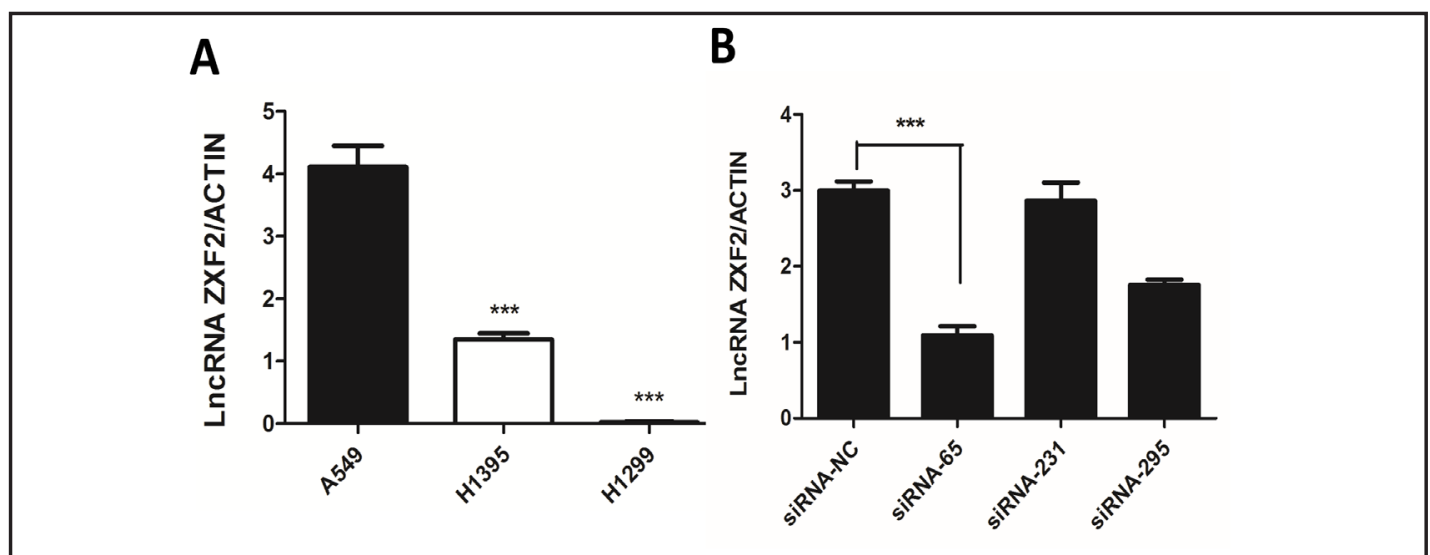

Fig. 2. LncRNA ZXF2 is overexpressed in A549, a high invasive and metastatic cell line. (A) LncRNA ZXF2 expression in different lung adenocarcinoma cell lines was determined by Western blot analysis. A549 cells had significantly higher expression compared with other two cell lines $(\mathrm{P}<0.01)$. (B) Three different interference sequences were originally designed to knockdown ZXF2 expression. Compared to siRNA-NC (negative control), transfection of siRNA-65 led to about 70\% reduction of ZXF2 expression, which showed the strongest inhibitory efficiency among three siRNAs probes.

\section{KARGER}


Cell Physiol Biochem 2015;35:2360-2370

DOI: 10.1159/000374038

Published online: April 15, 2015

(c) 2015 S. Karger AG, Basel

Yang et al.: Oncological Roles of LncRNA ZXF2 in Lung Cancers

To correlate the expression level of ZXF2 in tumor tissues with patients' clin icopatholog i cal parameters, we first equally divided patients into two groups using a cut-off of median using a relative ZXF2 expression value: the average level of ZXF2 in one group is 12.67 \pm 5.09 (ZXF2 high group) and that in the other group is $1.79 \pm 1.60$ (ZXF2 low group). Next, the association between ZXF2 expression in tumor tissues and clinicopathological features of patients with lung cancers was examined. The clinicopathological parameters of the two groups were summarized in Table 2. Multivariate analysis (Table 2) revealed that high expression of ZXF2 was positively correlated with histological grade $(\mathrm{p}=0.024), \mathrm{T}$ stage classification $\quad(\mathrm{p}=0.016)$, lymph node metastasis $(\mathrm{p}=0.014)$ and advanced clinical staging $(\mathrm{p}=0.006)$. No correlation was observed between ZXF2 expression and other factors such as age, gender, smoking history, tumor size and location $(\mathrm{P}>0.05)$. Furthermore, KaplanMeier survival curves revealed correlations between high ZXF2 expression and poor overall survival and recurrencefree survival (Fig. 1B, $\mathrm{p}<0.01$ ). Taken together, this analysis suggested that high expression of ZXF2 was closely correlated with tumor progression in human lung adenocarcinoma.
Table 2. The relationship between IncRNA ZXF2 expression and clinicopathological parameters of 40 patients with lung adenocarcinoma

\begin{tabular}{|c|c|c|c|c|}
\hline $\begin{array}{l}\text { Clinicopathological } \\
\text { features }\end{array}$ & $\begin{array}{l}\text { ZXF2 high levels } \\
\qquad(\mathrm{n}=20)\end{array}$ & $\begin{array}{l}\text { ZXF2 low levels } \\
\qquad(\mathrm{n}=20)\end{array}$ & Chi-square & P value \\
\hline Age & & & 1.290 & 0.256 \\
\hline$<60$ & 6 & 3 & & \\
\hline$\geq 60$ & 14 & 17 & & \\
\hline Gender & & & 0.417 & 0.519 \\
\hline Male & 9 & 7 & & \\
\hline Female & 11 & 13 & & \\
\hline Smoking history & & & 0.476 & 0.490 \\
\hline Yes & 13 & 15 & & \\
\hline No & 7 & 5 & & \\
\hline Location & & & 1.129 & 0.288 \\
\hline Central & 7 & 4 & & \\
\hline Peripheral & 13 & 16 & & \\
\hline Histological grade & & & 7.444 & 0.024 \\
\hline Low & 11 & 3 & & \\
\hline Middle & 6 & 9 & & \\
\hline High & 3 & 8 & & \\
\hline Size $(\mathrm{cm})$ & & & 0.125 & 0.723 \\
\hline$<3$ & 5 & 6 & & \\
\hline$\geq 3$ & 15 & 14 & & \\
\hline $\mathrm{T}$ stage classification & & & 8.307 & 0.016 \\
\hline $\mathrm{T} 1$ & 5 & 6 & & \\
\hline $\mathrm{T} 2$ & 5 & 12 & & \\
\hline $\mathrm{T} 3$ & 10 & 2 & & \\
\hline Lymph node metastasis & & & 8.485 & 0.014 \\
\hline No & 8 & 16 & & \\
\hline N1 & 7 & 4 & & \\
\hline N2 & 5 & 0 & & \\
\hline Advanced clinical staging & & & 7.619 & 0.006 \\
\hline $\mathrm{I}, \mathrm{II}$ & 10 & 18 & & \\
\hline III & 10 & 2 & & \\
\hline
\end{tabular}


ZXF2 regulates cell cycle, proliferation, migration and invasion of lung cancer cells

In order to elucidate molecular mechanism of ZXF2 in promoting lung cancer development, in vitro cell culture experiments were employed. We first tested the expression ZXF2 in A549, H1299, and H1395 lung adenocarcinoma cell lines by qRT-PCR. As shown in Fig. 2, A549 had highest level of ZXF2 among these cell lines ( $\mathrm{P}<0.01$, Fig.2A). Because A549 was reported to be a high invasive and metastatic lung adenocarcinoma cell line [11], we chose it in the following experiments. We used siRNA technology to specifically knockdown the endogenous ZXF2 in A549 cells.

Three different RNA interference sequences were originally designed in this study: siRNA-65: 5'-GCU GUU GGA UGU CAC ACA CTT-3'; siRNA-231: 5'-CCC AAA UCU UCC UUC AAA UTT-3'; siRNA-295: 5'-GCC UGU CCU CAA UCC CUA UTT-3'. Compared to negative control siRNA (5'-UUC UCC GAA CGU GUC ACG UTT-3'), transfection of siRNA-65 resulted in highest inhibitory efficiency among these three siRNAs, which led to about $70 \%$ reduction of ZXF2 expression, (Fig. 2B). Based on this result, we selected siRNA-65 in the following experiments to test the functions of ZXF2 in lung cancer cells.

We first tested the effect of siRNA on cell proliferation. We found that siRNA-ZXF2 treatment significantly suppressed proliferation at different time points compared to A549 cells treated with siRNA-NC $(\mathrm{P}<0.01$, Fig. $3 \mathrm{~A})$. In order to elucidate the mechanisms underlying siRNA-ZXF2 induced proliferation suppression, we investigated whether siRNAZXF2 treatment can induce cell death by flow cytometry. Interestingly, we did not observe obvious apoptosis in A549 cells treated with siRNA-ZXF2 (Fig. 3B-3D).

Then, we tested whether knockdown of ZXF2 can affect cell cycle. Flow cytometry analyses of cell cycle distribution revealed that reduction of ZXF2 resulted in a significant increase of cell number in the $G_{0} / G_{1}$ phase and a slight reduction in $S$ and $G_{2} / M$ phases compared with cells transfected with siRNA-NC as a control. $(\mathrm{P}<0.01$, Fig.4A-C, Table 3), indicating $G_{0} / G_{1}$ arrest might contribute to proliferation inhibition by siRNA-ZXF2. We further examined the changes of several cell cycle related proteins that are known involved in lung cancers. The results shown that knockdown of ZXF2 did not change the expression of p21, Cyclin B1, but resulted in down regulation of Cyclin D1, whereas transfection of siRNANC had no effects on these proteins (Fig. 4D). Given the fact that Cyclin D1 plays an important role in the proliferation and progression of lung cancers [12], the Western blot results were consistent with the cell cycle distribution.

Fig. 3. Knockdown of ZXF2 inhibits cell proliferation. (A) A549 cells transfected with siRNA-ZXF2 or SiRNA-NC and incubated for 24h, 48h, 72h, 96h, respectively. The cells were detected by CCK-8 assay, the bars indicate means \pm SDs $(n=8)$. (B-D) Flow cytometry analysis revealed that knockdown of ZXF2 does not induce apoptosis of A549 cells.
A

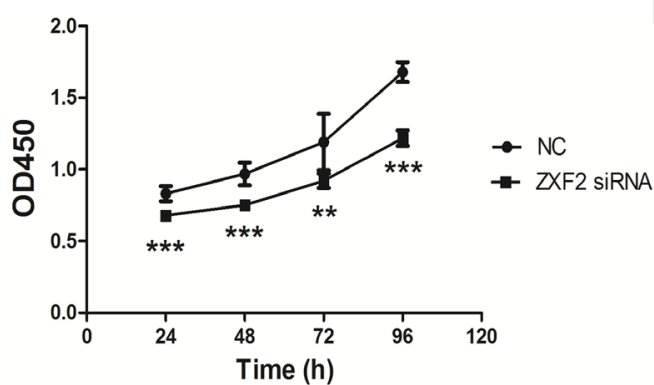

C

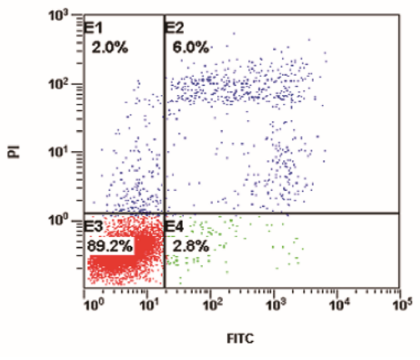

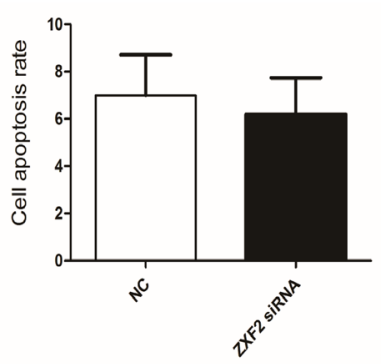

D

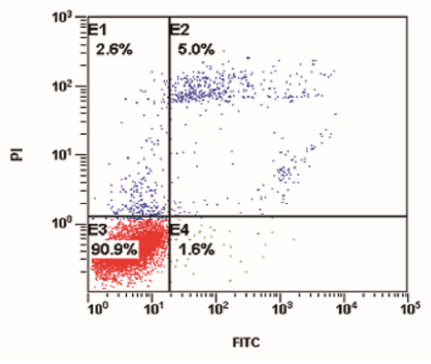




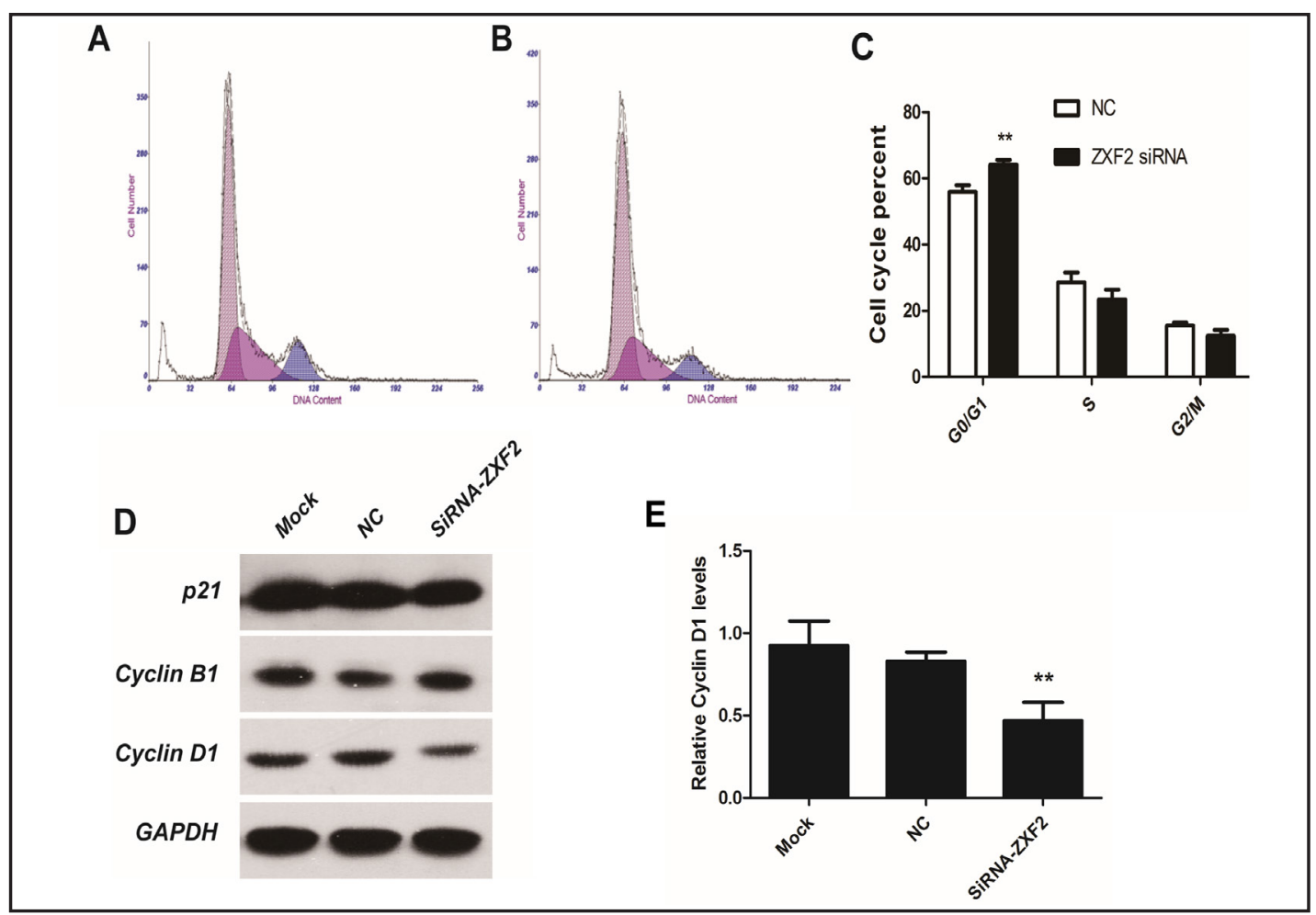

Fig. 4. Knockdown of ZXF2 leads to $G_{0} / G_{1}$ cell cycle arrest through down regulation of Cyclin D1 in A549 cells. Representative images of cell cycle distribution in siRNA-NC treatment group (A) and siRNA-ZXF2 treatment group (B). The data from (A) and (B) were summarized in (C), which showed $G_{0} / G_{1}$ cell cycle arrest after siRNA-ZXF2 treatment. The data indicate means \pm SD $(n=3, * *: p, 0.01)$. (D) The protein expression levels of p21, Cyclin B1, Cyclin D1 were detected by Western blot after transfected with siRNA-ZXF2. The expression of Cyclin D1 was decreased after siRNA-ZXF2 treatment, while the expression of p21 and Cyclin B1 did not change.

Table 3. Summary of cell cycle distribution of A549 cells treated with siRNA-ZXF2 and siRNA-NC control. **: $\mathrm{p}<0.01$

\begin{tabular}{lccc}
\hline \multirow{3}{*}{ Group } & \multicolumn{3}{c}{ Phase } \\
& $\mathrm{G}_{0} / \mathrm{G}_{1}{ }^{* *}$ & $\mathrm{~S}$ & $\mathrm{G}_{2} / \mathrm{M}$ \\
\hline SiRNA-NC & $(55.87 \pm 1.16) \%$ & $(28.62 \pm 1.68) \%$ & $(15.51 \pm 0.53) \%$ \\
SiRNA-ZXF2 & $(64.18 \pm 0.79) \%$ & $(23.41 \pm 1.72) \%$ & $(12.41 \pm 1.07) \%$ \\
\hline
\end{tabular}

We tested the potential function of ZXF2 on tumor cell migration and invasion. Boyden chamber transwell assay was used to determine cell migration and invasion capacities. After transfected with siRNA-ZXF2, both migration and invasion capacities were significantly inhibited as compared to those of cells treated with siRNA-NC. Specifically, the mean number of migrated cells per view in siRNA-ZXF2 treated group was $214.60 \pm 11.89$, while that in siRNA-NC treated group was $690.40 \pm 11.54$ (more than 3 -fold increase) $(\mathrm{P}<0.01$ ). In addition, we observed a more than 10 -fold reduction in invasive ability of the cells treated with siRNA-ZXF2 (57.80 \pm 4.73 cells/view in siRNA-ZXF2 treated group vs $628.20 \pm 7.08$ cells/view in siRNA-NC treated group; $\mathrm{P}<0.01$, Fig. 5A-F).

Knockdown of ZXF2 leads to inhibition of c-Myc signaling

In order to elucidate the molecular mechanisms of siRNA-ZXF2 mediated suppression of migration and invasion, two key proteins were selected. One was c-Myc which is a strong 


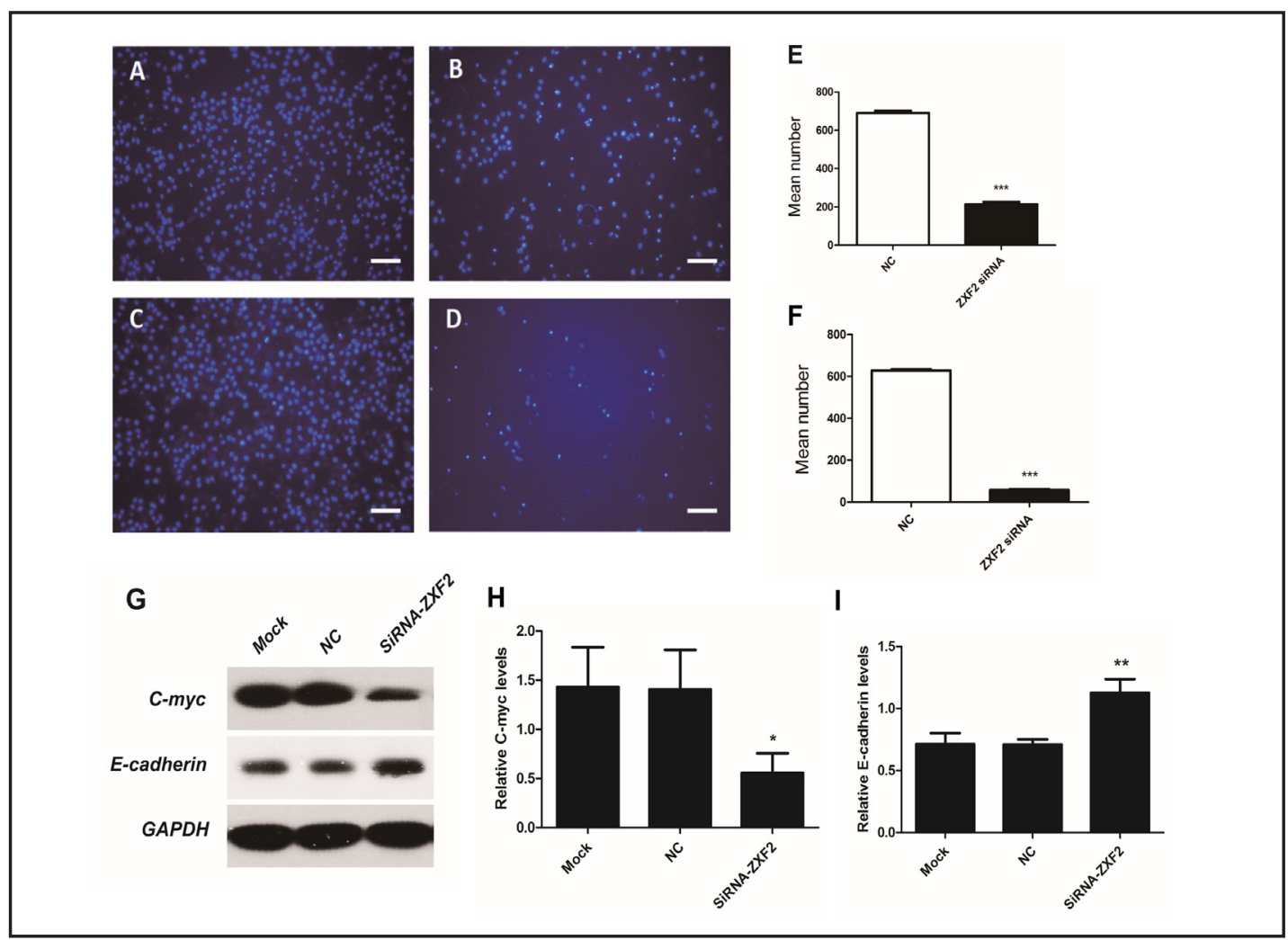

Fig. 5. Knockdown of ZXF2 inhibits migration and invasion through c-Myc/e-Cadherin signaling pathway. Transwell assay was used to detect migration and invasion of transfected A549 cells. The representative image showed siRNA-ZXF2 treatment (B) inhibited A549 cell migration as compared to those treated with siRNA-NC (A). Similarly, the representative images showed siRNA-ZXF2 treatment (D) inhibited A549 cell invasion as compared to those treated with siRNA-NC (C). (E) The number of migrated cells through filter was quantified by counting DAPI nuclear staining. Scale bar: $100 \mu \mathrm{m}$. The data represented means \pm SD $(n=5) .(F)$ The number of invaded cells was quantified by counting DAPI nuclear staining. Scale bar: 100 $\mu \mathrm{m}$. The data represented means $\pm \mathrm{SD}(\mathrm{n}=5)$. $(\mathrm{G})$ The protein expression levels of $c$-Myc and E-cadherin were detected by Western blot after transfected with siRNA-ZXF2 and control. The results showed that treatment of siRNA-ZXF2 led to down regulation of c-Myc and up regulation of E-cadherin. (H-I) Band densities of Western blot were quantified by densitometry. The results show a significant changes of expression of c-Myc and E-cadherin after siRNA-ZXF2 treatment. *: p<0.05; **: p<0.01.

proto-oncogene promoting cancer cell migration and invasion [13]. The other was E-cadherin which is frequently lost during tumor progression and transition to a more motile and invasive phenotype [14]. Interestingly, bioinformatics analysis revealed that both ZXF2 and c-Myc are adjacently located on 8q24.2 loci of human chromosome 8, which is a "hot spot" for multiple human cancers [15-17]. The Western blot analysis showed that transfection of siRNA-ZXF2 suppressed c-myc and enhanced e-cadherin expression, indicating a potential role of ZXF2 on controlling lung cancer progression through c-myc/e-cadherin pathway (Fig. $5 \mathrm{G}-5 \mathrm{I})$.

\section{Discussion}

It has been reported that $4 \%-9 \%$ of the transcription in mammalian genome are IncRNAs, whereas the rate of protein-coding RNA is only 1\%. Over a long period of time, lncRNA was considered as a "noise" in genome transcription without any biological 


\section{Cellular Physiology Cell Physiol Biochem 2015;35:2360-2370

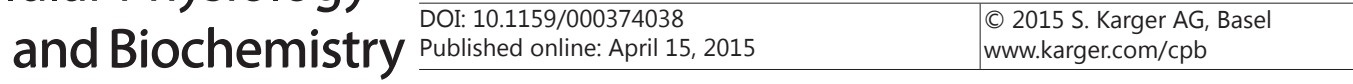 \\ Yang et al.: Oncological Roles of LncRNA ZXF2 in Lung Cancers}

functions. However, recent studies have showed that lncRNAs participate in a lot of critical biological regulations, such as X-chromosome silence, genomic imprinting and chromatin modification, transcription activation, transcription interference and nuclear transport et al. [4]. In recent years, increasing evidences have linked IncRNA to various biological processes and diseases [18]. For example, HOTAIR, one of the first lncRNAs, was reported to be involved in the progression of breast cancer [6]. Our group previously identified a group of IncRNAs that were differentially expressed between lung cancer tissues and adjacent normal tissues derived from patients with lung adenocarcinomas [8].

In the present study, we tested the functions of one of the novel lncRNAs, ZXF2 (located on chromosome 8, SEQ_ID:AA311918) in lung cancer progression. We found that expression of ZXF2 was increased in human lung cancer tissues, negatively correlated with post-surgery survival and positively correlated with lymph node metastasis of patients with lung cancers. We knockdowned ZXF2 in A549 cells, a metastatic lung cancer cell line, in order to explore the cellular and molecular mechanisms of potential tumor promoting function of ZXF2. We found that siRNA-ZXF2 treatment led to suppression of cell proliferation, migration and invasion, and $\mathrm{G}_{0} / \mathrm{G}_{1}$ arrest through regulating c-myc/e-cadherin pathway.

As development of cancer is a result of orchestration of a multiple genes network, some traditional approaches that targets single gene might only have limited effect on controlling tumor growth. Given this background, LncRNAs, which play an important role in regulation of transcription and post-transcription processes, might be a better approach for developing effective means to treat cancers. In the present study, we observed a very interesting phenomenon that ZXF2 can regulate tumor progression by targeting c-myc/e-cadherin pathway. C-myc has been shown to negatively regulate e-cadherin through activating the transcription of microRNA-9 in breast cancer cells [19], which was consistent with our observation. In addition, c-Myc can induce expression of Cyclin D1 to promote cell cycle progression in multiple systems [20, 21], and functional interactions between c-Myc and cylclin D1 play a critical role in tumor initiation, progression and response to chemotherapy [22]. Therefore, we suspect that our observation that knockdown of ZXF2 led to down regulation of Cyclin D1 could also be c-Myc dependent. The potential molecular mechanisms underlying ZXF2 mediated regulation of c-myc could be summarized as following: First, given the fact that both human c-myc and ZXF2 are adjacently located on chromosome 8 (8q24.2), and some lncRNAs have been demonstrated to control myc expression through regulate long-range interactions between the MYC promoter and its enhancers in cancer cells [23, 24], it is possible that ZXF2 functions as a transcriptional enhancer of MYC gene. Second, a recent elegant study show that IncRNA can directly bind and serve as a coactivator of c-Myc to activate transactivation functions of c-Myc [25]. Finally, lncRNA has been shown to regulate mRNA stability of c-Myc [26]. Further studies will confirm the mechanism involved in ZXF2 mediated regulation of c-Myc.

\section{Conclusion}

In conclusion, IncRNA ZXF2 was overexpressed in human lung adenocarcinoma. The high level of lncRNA ZXF2 was associated with lymph node metastasis and poor postoperative survival time. The overexpression of ZXF2 promoted proliferation, migration and invasion of cancer cell. The study revealed that ZXF2 might be an important marker in lung adenocarcinoma metastasis and might also be a therapeutic target in the treatment of lung adenocarcinoma.

\section{Acknowledgement}

This work was supported by National Natural Science Foundation of China (grant No. 81101775). 


\section{Cellular Physiology Cell Physiol Biochem 2015;35:2360-2370 \begin{tabular}{l|l|l}
\hline DOI: 10.1159/000374038 & (C) 2015 S. Karger AG, Basel
\end{tabular} www.karger.com/cpb \\ Yang et al.: Oncological Roles of LncRNA ZXF2 in Lung Cancers}

\section{Disclosure Statement}

The authors confirm that there is no conflict of interest.

\section{References}

1 Hellwig S, Bass BL: A starvation-induced noncoding RNA modulates expression of Dicer-regulated genes. Proc Natl Acad Sci U S A 2008;105:12897-12902.

2 Rinn JL, Chang HY: Genome regulation by long noncoding RNAs. Annu Rev Biochem 2012;81:145-166.

3 Ulitsky I, Bartel DP: lincRNAs: genomics, evolution, and mechanisms. Cell 2013;154:26-46.

$4 \quad$ Clark MB, Mattick JS: Long noncoding RNAs in cell biology. Semin Cell Dev Biol 2011;22:366-376.

5 Flockhart RJ, Webster DE, Qu K, Mascarenhas N, Kovalski J, Kretz M, Khavari PA: BRAFV600E remodels the melanocyte transcriptome and induces BANCR to regulate melanoma cell migration. Genome Res 2012;22:1006-1014.

6 Gupta RA, Shah N, Wang KC, Kim J, Horlings HM, Wong DJ, Tsai MC, Hung T, Argani P, Rinn JL, Wang Y, Brzoska P, Kong B, Li R, West RB, van de Vijver MJ, Sukumar S, Chang HY: Long non-coding RNA HOTAIR reprograms chromatin state to promote cancer metastasis. Nature 2010;464:1071-1076.

7 Panzitt K, Tschernatsch MM, Guelly C, Moustafa T, Stradner M, Strohmaier HM, Buck CR, Denk H, Schroeder R, Trauner M, Zatloukal K: Characterization of HULC, a novel gene with striking up-regulation in hepatocellular carcinoma, as noncoding RNA. Gastroenterology 2007;132:330-342.

8 Zhang L, Zhou XF, Pan GF, Zhao JP: Enhanced expression of long non-coding RNA ZXF1 promoted the invasion and metastasis in lung adenocarcinoma. Biomed Pharmacother 2014;68:401-407.

9 Yu BL, Peng XH, Zhao FP, Liu X, Lu J, Wang L, Li G, Chen HH, Li XP: MicroRNA-378 functions as an onco-miR in nasopharyngeal carcinoma by repressing TOB2 expression. Int J Oncol 2014;44:1215-1222.

10 Yu L, Lu J, Zhang B, Liu X, Wang L, Li SY, Peng XH, Xu X, Tian WD, Li XP: miR-26a inhibits invasion and metastasis of nasopharyngeal cancer by targeting EZH2. Oncol Lett 2013;5:1223-1228.

11 Yang L, Zeng W, Li D, Zhou R: Inhibition of cell proliferation, migration and invasion by DNAzyme targeting MMP-9 in A549 cells. Oncol Rep 2009;22:121-126.

12 Nguyen VN, Mirejovsky P, Mirejovsky T, Melinova L, Mandys V: Expression of cyclin D1, Ki-67 and PCNA in non-small cell lung cancer: prognostic significance and comparison with p53 and bcl-2. Acta Histochem 2000;102:323-338.

13 He X, Tan X, Wang X, Jin H, Liu L, Ma L, Yu H, Fan Z: C-Myc-activated long noncoding RNA CCAT1 promotes colon cancer cell proliferation and invasion. Tumour Biol 2014;10.1007/s13277-014-2526-4.

14 Mateen S, Raina K, Agarwal C, Chan D, Agarwal R: Silibinin synergizes with histone deacetylase and DNA methyltransferase inhibitors in upregulating E-cadherin expression together with inhibition of migration and invasion of human non-small cell lung cancer cells. J Pharmacol Exp Ther 2013;345:206-214.

15 Yeager M, Orr N, Hayes RB, Jacobs KB, Kraft P, Wacholder S, Minichiello MJ, Fearnhead P, Yu K, Chatterjee N, Wang Z, Welch R, Staats BJ, Calle EE, Feigelson HS, Thun MJ, Rodriguez C, Albanes D, Virtamo J, Weinstein S, Schumacher FR, Giovannucci E, Willett WC, Cancel-Tassin G, Cussenot O, Valeri A, Andriole GL, Gelmann EP, Tucker M, Gerhard DS, Fraumeni JF, Jr., Hoover R, Hunter DJ, Chanock SJ, Thomas G: Genome-wide association study of prostate cancer identifies a second risk locus at 8q24. Nat Genet 2007;39:645-649.

16 Haiman CA, Le Marchand L, Yamamato J, Stram DO, Sheng X, Kolonel LN, Wu AH, Reich D, Henderson BE: A common genetic risk factor for colorectal and prostate cancer. Nat Genet 2007;39:954-956.

17 Tomlinson I, Webb E, Carvajal-Carmona L, Broderick P, Kemp Z, Spain S, Penegar S, Chandler I, Gorman M, Wood W, Barclay E, Lubbe S, Martin L, Sellick G, Jaeger E, Hubner R, Wild R, Rowan A, Fielding S, Howarth K, Silver A, Atkin W, Muir K, Logan R, Kerr D, Johnstone E, Sieber O, Gray R, Thomas H, Peto J, Cazier JB, Houlston R: A genome-wide association scan of tag SNPs identifies a susceptibility variant for colorectal cancer at 8q24.21. Nat Genet 2007;39:984-988.

18 Yu W, Gius D, Onyango P, Muldoon-Jacobs K, Karp J, Feinberg AP, Cui H: Epigenetic silencing of tumour suppressor gene p15 by its antisense RNA. Nature 2008;451:202-206. 


\section{Cellular Physiology Cell Physiol Biochem 2015;35:2360-2370 and Biochemistry

19 Ma L, Young J, Prabhala H, Pan E, Mestdagh P, Muth D, Teruya-Feldstein J, Reinhardt F, Onder TT, Valastyan S, Westermann F, Speleman F, Vandesompele J, Weinberg RA: miR-9, a MYC/MYCN-activated microRNA, regulates E-cadherin and cancer metastasis. Nat Cell Biol 2010;12:247-256.

20 Robson SC, Ward L, Brown H, Turner H, Hunter E, Pelengaris S, Khan M: Deciphering c-MYC-regulated genes in two distinct tissues. BMC Genomics 2011;12:476.

21 Daksis JI, Lu RY, Facchini LM, Marhin WW, Penn LJ: Myc induces cyclin D1 expression in the absence of de novo protein synthesis and links mitogen-stimulated signal transduction to the cell cycle. Oncogene 1994;9:3635-3645.

22 Liao DJ, Thakur A, Wu J, Biliran H, Sarkar FH: Perspectives on c-Myc, Cyclin D1, and their interaction in cancer formation, progression, and response to chemotherapy. Crit Rev Oncog 2007;13:93-158.

23 Kim T, Cui R, Jeon YJ, Lee JH, Sim H, Park JK, Fadda P, Tili E, Nakanishi H, Huh MI, Kim SH, Cho JH, Sung BH, Peng Y, Lee TJ, Luo Z, Sun HL, Wei H, Alder H, Oh JS, Shim KS, Ko SB, Croce CM: Long-range interaction and correlation between MYC enhancer and oncogenic long noncoding RNA CARLo-5. Proc Natl Acad Sci U S A 2014;111:4173-4178.

24 Xiang JF, Yin QF, Chen T, Zhang Y, Zhang XO, Wu Z, Zhang S, Wang HB, Ge J, Lu X, Yang L, Chen LL: Human colorectal cancer-specific CCAT1-L lncRNA regulates long-range chromatin interactions at the MYC locus. Cell Res 2014;24:513-531.

25 Hung CL, Wang LY, Yu YL, Chen HW, Srivastava S, Petrovics G, Kung HJ: A long noncoding RNA connects c-Myc to tumor metabolism. Proc Natl Acad Sci U S A 2014;111:18697-18702.

26 Yang F, Xue X, Zheng L, Bi J, Zhou Y, Zhi K, Gu Y, Fang G: Long non-coding RNA GHET1 promotes gastric carcinoma cell proliferation by increasing c-Myc mRNA stability. FEBS J 2014;281:802-813. 